\title{
Observation of viscosity transition in $\alpha$-pinene secondary organic aerosol
}

\author{
Emma Järvinen ${ }^{1}$, Karoliina Ignatius ${ }^{2}$, Leonid Nichman ${ }^{3}$, Thomas B. Kristensen ${ }^{2}$, Claudia Fuchs ${ }^{4}$, \\ Christopher R. Hoyle ${ }^{4,8}$, Niko Höppel ${ }^{1}$, Joel C. Corbin ${ }^{4}$, Jill Craven ${ }^{5}$, Jonathan Duplissy ${ }^{6}$, Sebastian Ehrhart ${ }^{7}$, \\ Imad El Haddad ${ }^{4}$, Carla Frege ${ }^{4}$, Hamish Gordon ${ }^{7}$, Tuija Jokinen ${ }^{6}$, Peter Kallinger ${ }^{9}$, Jasper Kirkby ${ }^{7,10}$, \\ Alexei Kiselev ${ }^{1}$, Karl-Heinz Naumann ${ }^{1}$, Tuukka Petäjä ${ }^{6}$, Tamara Pinterich ${ }^{9}$, Andre S. H. Prevot ${ }^{4}$, Harald Saathoff $^{1}$, \\ Thea Schiebel ${ }^{1}$, Kamalika Sengupta ${ }^{11}$, Mario Simon ${ }^{10}$, Jay G. Slowik ${ }^{4}$, Jasmin Tröstl ${ }^{4}$, Annele Virtanen ${ }^{12}$, \\ Paul Vochezer ${ }^{1}$, Steffen Vogt ${ }^{1}$, Andrea C. Wagner ${ }^{10}$, Robert Wagner $^{1}$, Christina Williamson ${ }^{10,13,14}$, Paul M. Winkler ${ }^{9}$, \\ Chao Yan ${ }^{6}$, Urs Baltensperger ${ }^{4}$, Neil M. Donahue ${ }^{15}$, Rick C. Flagan ${ }^{16}$, Martin Gallagher ${ }^{3}$, Armin Hansel ${ }^{17}$, \\ Markku Kulmala ${ }^{6}$, Frank Stratmann ${ }^{2}$, Douglas R. Worsnop ${ }^{18}$, Ottmar Möhler ${ }^{1}$, Thomas Leisner ${ }^{1}$, and \\ Martin Schnaiter ${ }^{1}$ \\ ${ }^{1}$ Karlsruhe Institute of Technology, Institute for Meteorology and Climate Research, P.O. Box 3640, \\ 76021 Karlsruhe, Germany \\ ${ }^{2}$ Institute for Tropospheric Research (TROPOS), 04318 Leipzig, Germany \\ ${ }^{3}$ School of Earth, Atmospheric and Environmental Sciences, University of Manchester, Manchester, M13 9PL, UK \\ ${ }^{4}$ Laboratory of Atmospheric Chemistry, Paul Scherrer Institute, Villigen, Switzerland \\ ${ }^{5}$ California institute of technology, department of chemical engineering, Pasadena, CA 91125, USA \\ ${ }^{6}$ Helsinki Institute of Physics and University of Helsinki, Department of Physics, Helsinki, Finland \\ ${ }^{7}$ CERN, 1211, Geneva, Switzerland \\ ${ }^{8}$ WSL Institute for Snow and Avalanche Research SLF, Davos, Switzerland \\ ${ }^{9}$ Faculty of Physics, University of Vienna, Vienna, Austria \\ ${ }^{10}$ Institute for Atmospheric and Environmental Sciences, Goethe-University Frankfurt am Main, \\ Campus Riedberg Altenhöferallee 1, 60438 Frankfurt am Main, Germany \\ ${ }^{11}$ University of Leeds, School of Earth and Environment, LS2-9JT Leeds, UK \\ ${ }^{12}$ Department of Applied Physics, University of Eastern Finland, Kuopio, Finland \\ ${ }^{13}$ NOAA Earth Systems Research Laboratory (ESRL), Chemical Sciences Division, 325 Broadway, Boulder, \\ Colorado 80305, USA \\ ${ }^{14}$ Cooperative Institute for Research in Environmental Sciences (CIRES), University of Colorado Boulder, UCB 216, \\ Boulder, Colorado 80309, USA \\ ${ }^{15}$ Center for Atmospheric Particle Studies, Carnegie Mellon University, 5000 Forbes Ave., Pittsburgh, PA 15213, USA \\ ${ }^{16}$ California Institute of Technology, Division of Chemistry and Chemical Engineering, Pasadena, California 91125, USA \\ ${ }^{17}$ Institute for Ion and Applied Physics, 6020 Innsbruck and Ionicon Analytik GmbH, 6020 Innsbruck, Austria \\ ${ }^{18}$ Aerodyne Research, Inc., Billerica, MA 08121, USA
}

Correspondence to: Emma Järvinen (emma.jaervinen@kit.edu)

Received: 4 September 2015 - Published in Atmos. Chem. Phys. Discuss.: 22 October 2015

Revised: 8 March 2016 - Accepted: 29 March 2016 - Published: 11 April 2016 
Abstract. Under certain conditions, secondary organic aerosol (SOA) particles can exist in the atmosphere in an amorphous solid or semi-solid state. To determine their relevance to processes such as ice nucleation or chemistry occurring within particles requires knowledge of the temperature and relative humidity $(\mathrm{RH})$ range for SOA to exist in these states. In the Cosmics Leaving Outdoor Droplets (CLOUD) experiment at The European Organisation for Nuclear Research (CERN), we deployed a new in situ optical method to detect the viscous state of $\alpha$-pinene SOA particles and measured their transition from the amorphous highly viscous state to states of lower viscosity. The method is based on the depolarising properties of laboratory-produced non-spherical SOA particles and their transformation to non-depolarising spherical particles at relative humidities near the deliquescence point. We found that particles formed and grown in the chamber developed an asymmetric shape through coagulation. A transition to a spherical shape was observed as the $\mathrm{RH}$ was increased to between $35 \%$ at $-10{ }^{\circ} \mathrm{C}$ and $80 \%$ at $-38^{\circ} \mathrm{C}$, confirming previous calculations of the viscositytransition conditions. Consequently, $\alpha$-pinene SOA particles exist in a viscous state over a wide range of ambient conditions, including the cirrus region of the free troposphere. This has implications for the physical, chemical, and icenucleation properties of SOA and SOA-coated particles in the atmosphere.

\section{Introduction}

Organic particulate material is abundant in Earth's atmosphere. Biogenic and anthropogenic sources emit volatile organic compounds (VOCs), which are oxidized through a cascade of chemical reactions into extremely low volatility vapours that condense into the particle phase to form secondary organic aerosol (SOA) (Hallquist et al., 2009). Biogenic VOCs are much more abundant than anthropogenic VOCs (Guenther et al., 1995; Jimenez et al., 2009) and monoterpenes such as $\alpha$-pinene are found throughout the continental boundary layer, particularly in boreal forest regions (e.g., Tunved et al., 2006; Laaksonen et al., 2008). After formation, SOA influences climate on a global scale directly by scattering and absorbing solar radiation and indirectly through aerosol-cloud interactions. Locally, SOA can affect air quality and human health (e.g., Nel, 2005; Huang et al., 2014). However, the chemical and physical processes that determine the properties of SOA particles are complex, and our understanding of these processes is limited (Hallquist et al., 2009; Hoyle et al., 2011).

Recently, considerable attention has been given to water uptake and viscous properties of SOA. It has been found that SOA particles can exist in the atmosphere in an amorphous semi-solid or solid state (Virtanen et al., 2010; Koop et al., 2011; Renbaum-Wolff et al., 2013; Pajunoja et al., 2014).
The existence of these states has several atmospheric implications. Molecular diffusion in the condensed phase affects the gas uptake by viscous SOA particles and can, therefore, alter the SOA particle lifetime in the atmosphere (Shiraiwa et al., 2011). In addition, water uptake is inhibited in the viscous particles (Riipinen et al., 2012), limiting the SOA growth under conditions in which SOA would typically grow hygroscopically (Swietlicki et al., 2008; Pajunoja et al., 2015). This, in turn, influences the aerosol direct effect on radiative forcing. More recent studies have shown that the viscous SOA particles or their proxies can act as ice nuclei (IN) (Murray et al., 2010; Wagner et al., 2012; Wang et al., 2012; Wilson et al., 2012; Schill et al., 2014), thus influencing cloud cover, cloud optical properties, and precipitation.

In order to understand the climatological influence of the viscous state of SOA particles, detailed knowledge of the temperature and relative humidity $(\mathrm{RH})$ ranges in which SOA can persist in a solid or semi-solid state is needed. Several experimental methods have been developed to measure the transition temperature or RH between different SOA phase states. A direct way to measure the glass-transition temperature, $T_{\mathrm{g}}$, of SOA substances is to use differential scanning calorimetry (DSC; Zobrist et al., 2008). However, this method requires the removal of the semi-volatile aerosol particles from the surrounding gas, which can change the state, shape, or composition of the SOA particles (Zhang et al., 2015). In contrast, indirect methods allow for the sampling of the SOA particles with their surrounding gas. As indirect methods, they do not directly measure $T_{\mathrm{g}}$, but rather probe the change in the SOA particle mechanical or aerodynamical properties with temperature or RH. These methods include the bounce method that exploits the fact that solid or semi-solid particles rebound in an impactor plate, whereas liquid particles adhere. A low pressure impactor (ELPI; Virtanen et al., 2010; Saukko et al., 2012) has been used for this purpose and, recently, the method is extended to work at atmospheric pressures (Bateman et al., 2014). Moreover, the so-called poke-flow method (Renbaum-Wolff et al., 2013) and the shatter technique (Schill et al., 2014) use mechanical forces to disturb single particles and the response to the mechanical stress can be linked with a phase state. Finally, the particle phase state can be determined with measurement of their aerodynamic shape factor (Zhang et al., 2015).

Although these methods provide useful insights into the nature of the SOA particles, the SOA aerosol has been sampled and passed through an instrument, in which their environment is altered. This may result in a change in the material properties. In an effort to minimize biases due to these perturbations, we have employed a new optical method that provides a non-invasive probe of shape or structural anisotropy that may be present in solid or highly viscous semi-solid SOA particles (Virtanen et al., 2010; Adler et al., 2013; Pajunoja et al., 2014; Schill et al., 2014; Zhang et al., 2015), but that is quickly erased in low viscosity droplets as they relax 
toward the most energetically favourable state, i.e., spherical droplets that are homogeneous throughout their volumes.

For a perfectly isotropic, spherical particle, light that is scattered directly back toward its source, i.e., in a direction of $180^{\circ}$ from that of the incident light, retains its initial polarization state. Whether it results from deviations from spherical symmetry, or from structural inhomogeneities, anisotropy in the optical properties leads to depolarization. A measurement of the extent of depolarization in the backscattered light probes the magnitude of the anisotropy and, hence, the ability of the particle to relax to its low-energy state. This signal thus reflects the viscosity of the material that comprises the particle, provided that some mechanism has previously introduced anisotropy.

Here, we present a new approach based on in situ measurement of depolarization, and use it to study the effect of temperature and $\mathrm{RH}$ on the viscosity transitions that SOA particles may undergo as they become solvated with water at high humidity. This paper is organized as follows. The new method depends on how different types of anisotropy affect depolarization of light scatted by the small (sub-micron) SOA particles that are found in the atmosphere. We begin, therefore, with theoretical and modelling studies of the effects of size, shape, and internal structure on the depolarization signals that we may expect. The modelling studies allow us to constrain the range of particle sizes and concentrations for which the method is useful, and proved central to the design and optimization of an instrument capable of measuring the viscous transition under atmospheric conditions. Moreover, they aid in understanding the relative importance of shape and structural anisotropy in the measurements.

We then describe the experimental method, the instrument that has been developed, and instrument characterization experiments that assess the limits to the sensitivity of the depolarization measurements. We define an instrumentalbased viscosity-/shape-transition $\mathrm{RH}$ that describes the $\mathrm{RH}$ value, where the particles were observed to be spherical or isotropic according to our method. The viscosity/shape transitions are measured for a model SOA system, i.e. the SOA produced by oxidation of $\alpha$-pinene. The experiments were conducted in the The European Organization for $\mathrm{Nu}$ clear Research (CERN) Cosmics Leaving Outdoor Droplets (CLOUD) chamber, an environmental chamber that has unique capabilities to simulate conditions throughout the troposphere while maintaining the cleanliness required for new particle formation studies (Schnitzhofer et al., 2014). We describe the experimental facility, key measurement methods that were employed, and experimental procedures.

Experimental results are described, beginning with those from the instrument characterization studies, but then focusing on the dynamics of the SOA particles, the evolution of their properties, and the viscosity/shape transition of the $\alpha$ pinene SOA. We continue the paper with a discussion of the atmospheric implications of our findings, and finish with conclusions.

\section{Theoretical considerations}

The depolarization ratio is a measure of how strongly the polarization state of incident light is altered during scattering by particles. Isotropic spherical particles do not induce linear or circular depolarization in the exact backward direction, whereas non-spherical particles alter the depolarization state of incident light depending on their size, shape, and refractive index. Therefore, depolarization measurements can be used to determine the particle asphericity. The magnitude of the depolarization ratio can, in the case of aerosol particles, vary from only a few per cent (in the case of sea salt) to up to 0.4 (in the case of dust aerosol) (Sakai et al., 2010). Solid or semi-solid amorphous particles may also induce depolarization due to internal structures or inhomogeneous refractive index. In this case the depolarization will depend on the gradient and/or variation of the refractive index as well as the size of the particle. In the case of sub-micron particles, the scale of the variation in particle properties is restricted by the size, and hence we can expect a maximum depolarization ratio of 0.01 due to particle inhomogenities, whereas the probable depolarization ratios are well below that ( $\mathrm{Li}$ et al., 2005; Dlugach and Mishchenko, 2015).

To quantify the extent of depolarization, we define the depolarization ratio, $\delta_{\mathrm{L}, \mathrm{C}}$ (indices $\mathrm{L}, \mathrm{C}$ denoting the liner or circular incident depolarization state) as the ratio of the intensity of the parallel polarized light, $I_{\|}$, to the perpendicular polarized light, $I_{\perp}$, in the backscatter direction when the particle is illuminated with perpendicularly polarized light. For a perfect measurement, we could take the ratio directly. In any real measurement there will be some background contribution to these two signals in the form of molecular scattering and scattering from chamber walls. Therefore, we subtract the background intensities $I_{\|}^{\mathrm{bg}}$ and $I_{\perp}^{\mathrm{bg}}$ measured in the absence of scattering particles from the measured scattered light intensities during particle measurements, defining $\delta_{\mathrm{L}, \mathrm{C}}$ as

$\delta_{\mathrm{L}, \mathrm{C}}=\frac{I_{\|}-I_{\|}^{\mathrm{bg}}}{I_{\perp}-I_{\perp}^{\mathrm{bg}}}$.

We modelled the depolarization ratio to assess the sensitivity of this method to the small particles that are produced in the environmental chamber and that will be used for studies of the viscosity transition. We ignore the effect of anisotropy and consider only the influence of the particle asphericity on the depolarization ratio. This can be estimated using a $T$-matrix approach in a regime that is appropriate for particles, whose size is of the order of the wavelength of the incident light (Mishchenko et al., 1996). We performed $T$-matrix computations using the aforementioned constraints to model the expected depolarization properties of growing SOA particles in our experiments. The simulations were done for a particle size distributions with geometric mean diameters (GMD) ranging from 100 to $1400 \mathrm{~nm}$ and 
with a narrow geometric standard deviation (GSD) of 1.1, as would be expected when the primary growth mechanism is condenzation. The refractive index of $\alpha$-pinene SOA a nearroom temperatures has been shown to vary between 1.4 and 1.6 (Schnaiter et al., 2005; Kim et al., 2010; Redmond and Thompson, 2011). As we do not have the information on the refractive index of viscous $\alpha$-pinene SOA particles, we assumed in the modelling study a refractive index of $1.5+0 i$ after Schnaiter et al. (2005). Further details on the computational procedures used to model particle depolarization ratios can be found in Schnaiter et al. (2012).

\subsection{Simulation results}

The SOA particles were modelled with prolate spheroids. Prolate spheroids have a greater polar radius than equatorial radius, having the form of a symmetrical egg. In the $T$-matrix formalism the aspect ratio of these particles describes the relationship of the equatorial radius to the polar radius and is therefore always smaller than 1 (Fig. 1). Since the aspect ratio of the SOA particles is unknown, we performed the calculations with aspect ratios ranging from 0.91 to 0.5 (Fig. 2), where the largest aspect ratio of 0.91 represents the smallest deviation from a spherical shape and the smallest aspect ratio of 0.5 the largest deviation. Figure 2 shows that both the linear and circular depolarization ratios increase with increasing GMD of the particles. The increase in the depolarization ratio is significant up to $800 \mathrm{~nm}$, whereafter the influence of the size of the particles decreases. Moreover, the higher the aspect ratio (the closer the particles are to being spherical), the lower is the expected depolarization ratio. In the least aspherical case (aspect ratio 0.91), we estimate that the SOA particles have close to zero depolarization ratios at GMD below $400 \mathrm{~nm}$ and a maximum depolarization ratio that is close to 0.1 (linear depolarization) or to 0.25 (circular depolarization) at GMD of $1400 \mathrm{~nm}$.

As a result of these modelling studies, we can estimate that the internal inhomogeneity of SOA particles will most likely have only small, almost negligible effect on the depolarization ratio and that the depolarization ratio is mainly determined by the degree of particle asphericity. The $T$-matrix results showed that the particles with a GMD from 50 to $800 \mathrm{~nm}$ will only produce extremely small depolarization ratios, which will be challenging for the depolarization measurements. A high degree of sensitivity is required for the depolarization instrument; otherwise, the particles would require growth to sizes larger than $1 \mu \mathrm{m}$.
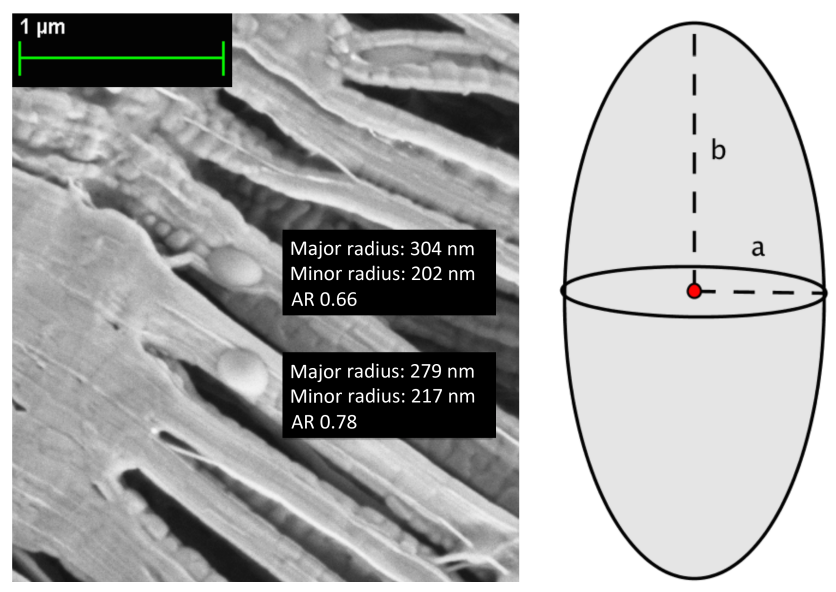

Figure 1. The SOA particles were modelled as prolate spheroids. An Environmental scanning electron microscope (ESEM) image of the SOA particles sampled from the CLOUD chamber show a spheroidal "egg-like" shape. The shape of the SOA particles in the ESEM images does not necessary resemble the real shape of the particles in the chamber, due to sampling conditions. In the $T$ matrix notation the aspect ratio (AR) is determined as the relation between the equatorial radius and the polar radius ( $\mathrm{a} / \mathrm{b}$ ) and is thus $<1$ for prolate spheroids.

\section{Experimental methods}

\subsection{Depolarization measurements}

We developed a new in situ depolarization instrument, SIMONE$^{1}$-Junior, with the necessary sensitivity to detect very low depolarization ratios. SIMONE-Junior is based on the design of the first SIMONE instrument (Schnaiter et al., 2012), which is installed at the cloud chamber facility Aerosol Interactions and Dynamics in the Atmosphere (AIDA) of the Karlsruhe Institute of Technology, with few improvements that have been implemented to attain the sensitivity and stability requirements that were identified in the simulations. SIMONE-Junior uses a continuous wave $(\mathrm{cw})$ laser (Coherent $552 \mathrm{~nm}$ OBIS laser, $20 \mathrm{~mW}$ ) to create a polarized and collimated light beam that is directed horizontally across the chamber (Fig. 3). The incident linear polarization state of the laser beam can be aligned either parallel or perpendicular to the scattering plane by a liquid crystal polarization rotator. Moreover, in contrast to the AIDA SIMONE, a liquid crystal variable retarder, able to be operated as a quarter-wave plate, was introduced to the system to allow generation of circularly polarized light. The orientation of the circular depolarization can be changed from right handed to left handed, although in this study we used only right-handed circular incident polarization.

\footnotetext{
${ }^{1}$ SIMONE is the acronym for the German project title Streulicht intensitätsmessungen zum optischen Nachweis von Eispartikeln, which means scattering intensity measurements for the optical detection of ice particles.
} 

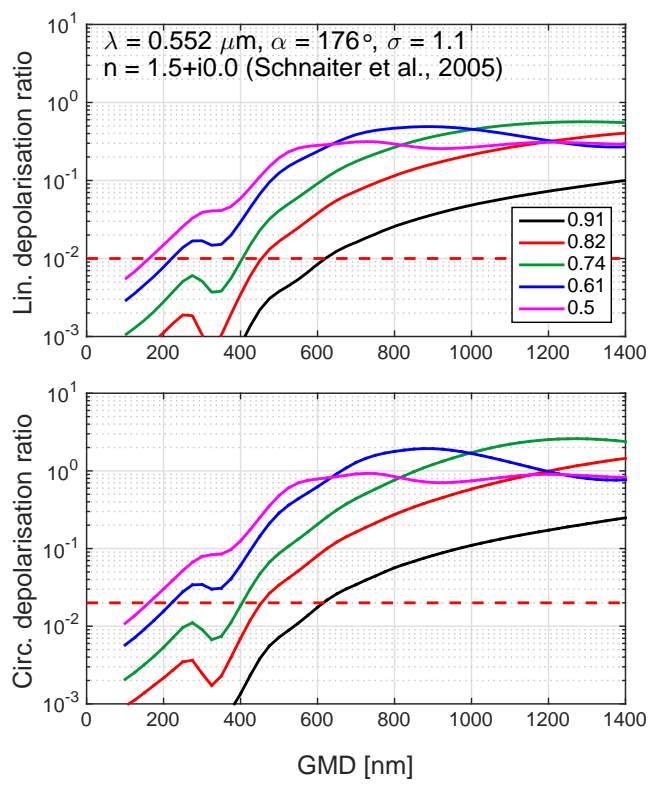

Figure 2. To plan the experiment, the expected linear and circular depolarization ratios were modelled with the $T$-matrix model assuming a spheroidal shape. A narrow particle size distribution with a constant GSD of 1.1 was used in the model and the GMD of the particles was varied from 0 to $1400 \mathrm{~nm}$ ( $x$ axis). The calculation was made for five spheroidal shapes with aspect ratios ranging from 0.91 to 0.5 . The detection thresholds of the SIMONE-Junior instrument (1\% for linear depolarization and $2 \%$ for circular) are indicated as dashed red horizontal lines. The modelling study indicates that the SOA particles need to be grown past $600 \mathrm{~nm}$ to produce a detectable depolarization ratio at aspect ratios up to 0.91 .

Two telescopes collect the laser light scattered from the centre of the aerosol chamber at an angle of $4^{\circ}$ in the forward direction and $176^{\circ}$ in the backward direction. While the intensity in the forward scattering angle is directly measured with a photonmultiplier tube, the intensity in the backward scattering angle is decomposed into its polarization components by a Wollaston prism. In the case of circular polarization, the scattered light is first retarded to linear polarization with a second liquid crystal variable retarder before the Wollaston prism.

\subsection{Experimental set-up}

The experiments presented here were conducted at the CERN CLOUD chamber (Kirkby et al., 2011; Duplissy et al., 2015; Hoyle et al., 2016) during the CLOUD8 (NovemberDecember 2013) and CLOUD9 campaigns (SeptemberNovember 2014). The chamber consists of a $26 \mathrm{~m}^{3}$ stainless steel cylinder that is located inside a thermally insulated housing. The temperature of the chamber can vary from -60 to $100^{\circ} \mathrm{C}$ and is controlled by regulating the temperature of air flowing around the chamber and inside the thermal housing. During the CLOUD8 and CLOUD9 campaigns, the tem-

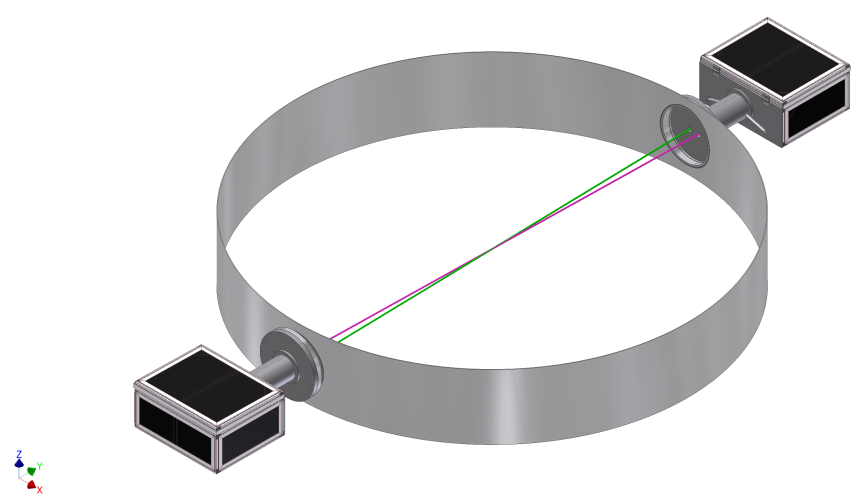

Figure 3. The SIMONE set-up at the CERN CLOUD chamber. The instrument consists of two boxes facing each other. One box houses the laser production and the backward scattered light detector and the other box houses the forward scattered light detector and a beam dump. The green line illustrates the path of the laser beam, which crosses the field of view (purple line) of the detection optics. The overlap region defines a detection volume of a few cubic centimetres volume in the centre of the chamber

perature inside the chamber was measured with a string of six thermocouples positioned horizontally at different distances between the wall and the chamber centre. We used the mean of the thermocouples as a representative measure of the temperature in the chamber volume.

In the course of the experiments, air from the chamber was constantly sampled; and this sampled air was replaced with humidified artificial air to maintain a constant pressure inside the chamber. The artificial air was created by evaporating liquid nitrogen and oxygen, and humidified by passing part of the flow through a Nafion humidifier to achieve a chosen constant RH. Alternatively, the air was passed through a heated line to the chamber, allowing the dew point of the incoming air to be higher than that in the chamber. The heated line was used at temperatures of $-30^{\circ} \mathrm{C}$ or lower, to enable rapid $\mathrm{RH}$ increase. The water vapour was mixed with the main air stream before entering the chamber, which allowed a homogeneous RH throughout the chamber volume after a mixing time of few minutes (Voigtländer et al., 2012). The RH inside the chamber was measured with a chilled mirror dew point hygrometer (MBW; model 973). During CLOUD9 a tuneable diode laser (TDL system) was used to measure water vapour, in addition to the MBW. The newly installed tuneable diode laser system will be described in more detail in the following section.

SOA particles were produced within the CLOUD chamber by ozonolysis of gaseous $\alpha$-pinene; the two reactant gases were separately fed into the chamber through mass flow controllers. The ozone was monitored with a trace gas monitor $\left(\mathrm{O}_{3}\right.$ analyser, Thermo Environmental Instruments, Inc., Model 49C); $\alpha$-pinene was measured by a Proton Transfer Reaction Time of Flight Mass Spectrometer (PTR-TOF; Ionicon Analytic). The ozone concentration was continu- 
ously measured, but, due to high concentrations of $\alpha$-pinene (over $600 \mathrm{ppbv}$ ), the PTR-TOF signal saturated, so it could not be measure continuously. The production of SOA was enhanced by ultraviolet (UV) photolysis of ozone to form OH (hydroxyl) radicals. A $50 \mathrm{~W}$ UV source (Philips TUV $130 \mathrm{~W}$ XPT lamp) was installed in a quartz tube inserted into the chamber. The formed $\mathrm{OH}$ oxidized $\alpha$-pinene to produce lower volatility organic vapours that nucleated and grew the aerosol particles.

Supporting measurements were provided by a range of instruments that were used to measure the physical and chemical composition of the aerosol particles inside the chamber. The chemical composition of the sub-micron aerosol particles was measured with an Aerodyne high-resolution time-of-flight aerosol mass spectrometer (HR-ToF-AMS). From these measurements the atomic oxygen to carbon ratio $(\mathrm{O} / \mathrm{C})$ was determined. The size distribution of the aerosol particles was measured with an Ultra-High Sensitivity Aerosol Spectrometer (UHSAS; DMT), which measures the optical sphere equivalent diameter of the particles in a size range from approximately 60 to $1000 \mathrm{~nm}$ and with a Scattering Mobility Particle Sizer (SMPS), which measures the mobility diameter between 30 and $500 \mathrm{~nm}$. The total concentration of aerosol particles was measured with a Condenzation Particle Counter (CPC; TSI 3010) with a $10 \mathrm{~nm}$ cutoff and with a maximum detectable particle concentration of $10000 \mathrm{~cm}^{-3}$ without coincidence corrections.

\subsubsection{Relative humidity measurements}

During the CLOUD9 campaign a tuneable diode laser (TDL) hygrometer, comparable to the APicT (AIDA PCI (Physical Chemistry Institute) in-cloud TDL) instrument as described by Fahey et al. (2014), was used to measure the water vapour content in situ. The TDL has $1 \mathrm{~Hz}$ time resolution and employs a single optical path of $314 \mathrm{~cm}$ once across the midplane of the CERN CLOUD chamber. Its main component is a temperature controlled, $10 \mathrm{~mW}$ distributed feedback diode laser (NTT Electronics) at a wavelength of $(1370 \pm 1) \mathrm{nm}$. The water absorption line was fitted online to determine water concentrations based on well-known spectroscopic constants. The windows mounted on the chamber limited the measurement range to between 30 and $1300 \mathrm{~Pa}$ water vapour pressure (300 and $13000 \mathrm{ppm}$ mixing ratio); the measurement uncertainty was $\pm 7 \%$ above $100 \mathrm{~Pa}$ and $\pm 10 \%$ between 30 and $100 \mathrm{~Pa}$. The relative humidity in the CLOUD chamber was calculated using these humidity data together with the average temperatures measured with a horizontal string of four calibrated thermocouples at the mid-plane of the chamber. The TDL hygrometer data enabled determination of the relative humidity even in the presence of clouds in the chamber, with an uncertainty of $\pm 10 \%$ above $100 \mathrm{~Pa}$ and $\pm 13 \%$ between 30 and $100 \mathrm{~Pa}$ water vapour pressure. The total humidity in the CLOUD chamber was also derived from the measurements from dew point hygrometer (model
MBW973, MBW calibration Ltd.) attached to a heated sampling line.

\subsubsection{Experimental procedure}

The aim of the experiments was to determine if a slightly aspherical particle shape or internal inhomogeneity of the viscous amorphous SOA could be detected by sensitive, nearbackscatter depolarization measurements and, if so, to observe the transition from irregular to a spherical shape during $\mathrm{RH}$ change. The range of experiments required was determined using the $T$-matrix modelling together with the lowest detection limit of the SIMONE-Junior instrument as guidelines. Figure 2 demonstrates that, in order to measure a significant depolarization signal with the highest aspect ratio (0.91), particles with a GMD of at least $600 \mathrm{~nm}$ must be generated. Furthermore, in contrast to atmospheric lidar applications (e.g., Sassen, 1991; Hirsikko et al., 2014), the detection volume of the SIMONE-Junior instrument is small, around a few tens of cubic centimetres. This means that we would need a high concentration to have enough particles inside this small detection volume to produce measurable signals. We estimated that an initial concentration of $10000 \mathrm{~cm}^{-3}$ newly formed SOA particles would produce adequate signals once the particles reached the size of $600 \mathrm{~nm}$.

Each experiment commenced with clean, aerosol-free air (background concentration well below $1 \mathrm{~cm}^{-3}$ and low $\mathrm{RH}$ (ranging from 5 to $15 \%$ ). The chamber was kept at 5 mbar overpressure to avoid underpressure in the sampling instruments. The SOA particles were generated and grown in the chamber by continuous oxidation of $\alpha$-pinene (maximum concentration $\sim 600 \mathrm{ppbv}$ ) with ozone (maximum concentration $\sim 700 \mathrm{ppbv}$ ), and $\mathrm{OH}$ radicals to form low volatility oxidized organic compounds. SOA nucleation was initiated by injecting $\alpha$-pinene $\left(10 \mathrm{~mL} \mathrm{~min}^{-1}\right)$ and ozone $\left(1000 \mathrm{~mL} \mathrm{~min}^{-1}\right)$ into the chamber simultaneously for 1 to 7 min, depending on the chamber temperature, and then turning on the UV light. After $1 \mathrm{~min}$ the $\alpha$-pinene flow was turned off until the freshly nucleated particles had grown to a mean diameter of approximately $100 \mathrm{~nm}$. This produced a nearmonodisperse particle population. At this point the $\alpha$-pinene flow was turned back on and continuously injected into the chamber in order to grow the existing particles without inducing further new particle formation. The initial particle burst typically comprised around $50000-100000 \mathrm{~cm}^{-3} \alpha$ pinene SOA particles, which rapidly grew to about $20 \mathrm{~nm}$ diameter. After the particles had grown to diameters of approximately $600 \mathrm{~nm}$, losses due to dilution, coagulation, and the chamber walls had reduced the particle number concentration to $5000-10000 \mathrm{~cm}^{-3}$. After a significant depolarization signal had been detected, we increased the RH in the chamber to search for a transition to the liquid phase. The RH was gradually increased by injecting humidified air (RH $100 \%$ ) into the chamber while simultaneously mixing the air inside the chamber with fans. This was continued until the depolar- 
Table 1. Experiment list with experiment run number, starting temperature, relative humidity at the beginning, particle size before transition started, and measured relative humidity range for the viscosity transition.

\begin{tabular}{llrrll}
\hline Run & CLOUD run number & $T\left[{ }^{\circ} \mathrm{C}\right]$ & Start RH [\%] & $\begin{array}{l}\text { Transition mode } \\
\text { mean diameter [nm] }\end{array}$ & $\begin{array}{l}\text { Viscosity } \\
\text { transition RH [\%] }\end{array}$ \\
\hline RUN_10C & CLOUD8 1313 & 10 & 12 & no transition & no transition \\
RUN1_-10C & CLOUD8 1314 & -10 & 12 & 560 & $23-35$ \\
RUN2_-10C & CLOUD9 1511 & -10 & 12 & 880 & $31-36$ \\
RUN1_-20C & CLOUD9 1512 & -20 & 10 & $500,850^{\mathrm{b}}$ & $44-49$ \\
REF_-20C & CLOUD9 1513 & -20 & $60^{\mathrm{a}}$ & no transition & no transition \\
RUN2_-20C & CLOUD9 1514 & -20 & 4 & 1000 & $41-45$ \\
RUN_-30C & CLOUD9 1515 & -30 & 2 & $500,850^{\mathrm{b}}$ & $55-62$ \\
RUN_-38C & CLOUD9 1516 & -38 & 5 & 630 & $69-79$ \\
\hline
\end{tabular}

${ }^{\mathrm{a}} \mathrm{RH}$ varied between 60 and $70 \% .{ }^{\mathrm{b}}$ More than one mode present.

ization signal had decreased to a constant zero-level. These experiments were performed at four different temperatures: $-10,-20,-30$, and $-38^{\circ} \mathrm{C}$.

In addition to these transition experiments, we performed one reference run with a higher starting $\mathrm{RH}(60-70 \%)$ at $-20^{\circ} \mathrm{C}$. The nucleation and growth of the $\alpha$-pinene SOA particles was conducted in the same way as the other experiments but the high RH was kept constant throughout. The purpose of this reference run was to produce a similar size distribution of $\alpha$-pinene SOA particles as in the viscositytransition runs, while ensuring that the state of the particles did not change, i.e., remained liquid, so they could not induce depolarization. This run was used to verify the depolarization method for a SOA system and to exclude the possibility of artefacts. The operating conditions for the reference run and all the viscosity-transition runs are listed in Table 1.

\section{Results and discussion}

\subsection{Sensitivity of the depolarization measurements}

Imperfect alignment and non-ideal behaviour of the optical components can induce crosstalk between the parallel and perpendicular channels in the backward scattering direction; i.e., in the perpendicular channel a percentage of the parallel intensity is measured and vice versa. This crosstalk ultimately determines the limit of detection (LOD) for the depolarization ratio. The LOD can also be defined as the depolarization crosstalk that is measured in the case of spherical particles.

To determine the LOD, we measured the depolarization ratio of laboratory-generated sulfuric acid (SA) solution droplets. SA droplets are known to be spherical (e.g., Schnaiter et al., 2012), and since in the calibration we restrict to sub-micrometre sizes, the SA particles should not introduce linear or circular depolarization at the measurement angle of SIMONE-Junior. Nevertheless, we measured a finite depolarization in the calibration experiments; this signal rep- resents the crosstalk from the parallel channel to the perpendicular channel. To minimize this depolarization crosstalk, we optimized the alignment of the optical components by separately rotating the optical planes of each component until a minimum depolarization signal was measured. The minimum crosstalk depolarization signal in the case of linear (parallel) incident polarization was 0.002 , and, in the case of circular (right-handed) incident polarization, 0.015. Moreover, it has to be kept in mind that the alignment of the instrument may change over time, as the instrument is mounted on a chamber (Sect. 3.2, Fig. 3), whose walls move during the 200 mbar pressure expansions used for other experiments (a maximum displacement of $0.5^{\circ}$ was observed), and may not return to the exact original position. This also means that the LOD will increase from the calibration value. To be absolutely confident that a measured depolarization signal is significant, we specified the LOD for linear depolarization to be 0.01 and for circular depolarization to be 0.02 . If the depolarization ratio is below these thresholds, we consider the particles indistinguishable from spherical according to our method.

\subsection{Growth and coagulation of the $\alpha$-pinene SOA particles}

We performed eight SOA nucleation and growth experiments in the CLOUD chamber using identical initial conditions described in Sect. 3.2.2. Each experiment resulted in a nucleation event that was followed by rapid growth of the $\alpha$-pinene SOA particles, producing a narrow particle size mode. Two examples of the growth of a single narrow mode are shown in Figs. 4 and 5. We fitted a log-normal distribution to the particle size distribution data to retrieve GMD and GSD. The GMD are shown in the first panels, and the GSD together with number concentration in the second panels. From the log-normal fit results, we see that the two runs presented in Figs. 4 and 5 are almost identical with respect to the particle size distribution, even though they were conducted at different temperature and humidity conditions. Both size dis- 


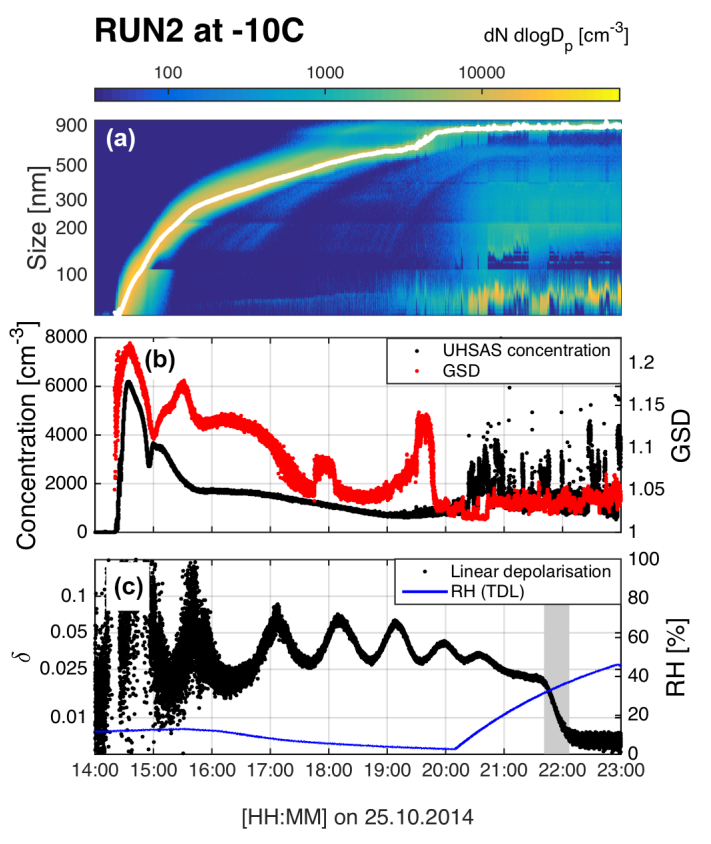

Figure 4. Overview of RUN2 at $-10^{\circ} \mathrm{C}$. The particle size distribution and the GMD from a log-normal fit are shown in panel (a). Panel (b) shows the total concentration measured with the UHSAS (with $56 \mathrm{~nm}$ cut-off) and the GSD determined from a log-normal fit. Panel (c) shows the linear depolarization ratio and $\mathrm{RH}$. The RH was kept low during the growth of the SOA particles, allowing them to remain in a viscous state. The RH was raised after about 20:15 UTC in order to measure its value at the particle phase transition from highly viscous to low viscosity state. The gradual phase transition began at 21:41 UTC and is indicated by the grey area in panel (c). The top and middle panels show further particle nucleation starting around 19:00 UTC; these particles remained relatively small and did not affect the measurement.

tributions are narrow with GSD variations between 1.05 and 1.2 , and show similar total number concentrations. In each case, particles grew beyond $700 \mathrm{~nm}$. The similarities between these two runs is important for interpreting the depolarization signals, as will be shown later.

Continuous addition of trace gases during RUN1_-20C, RUN_-30C, and RUN_-38C led to undesired nucleation events leading to a bimodal distribution of large (main mode with highest concentration) and small particles (secondary nucleation). The additional nucleation event always occurred before the viscosity-transition RH was reached, so we can assume that the state of the newly formed $\alpha$-pinene SOA particles was highly viscous. This assumption will be verified later with the depolarization data.

The high SOA particle concentration led to the formation of aggregates by coagulation inside the chamber. The coagulation process becomes an important determinant for the shape of the particles at sizes larger than $30 \mathrm{~nm}$; it has been suggested that sub-30 nm SOA particles are sufficiently liquid (Virtanen et al., 2011) that they coalescence upon coagu-

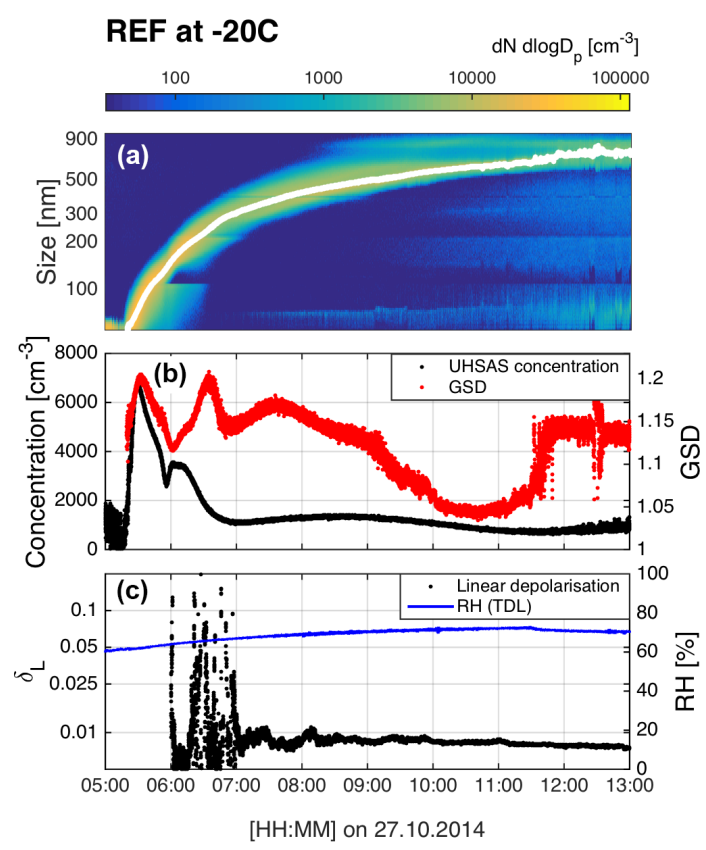

Figure 5. Overview of the reference run at $-20^{\circ} \mathrm{C}$. As for Fig. 4, panel (a) shows the particle size distribution and the GMD from a log-normal fit. Panel (b) shows the total concentration measured with the UHSAS (with $56 \mathrm{~nm}$ cut-off) and the GSD determined from a log-normal fit. Panel (c) shows the time development of the linear depolarization ratio and the $\mathrm{RH}$. During the reference run the $\mathrm{RH}$ was kept over $60 \%$ during the growth of the SOA particles to ensure that they remained in low viscous state during growth. At the beginning of the growth (06:00-07:00), the SOA particles were too small to efficiently scatter light and the signal shown in panel (c) at that time is mostly noise. After the particles were larger than $100 \mathrm{~nm}$, the linear depolarization ratio stayed below the detection threshold, indicating a low viscous state of the particles and verifying the absence of measurement artefacts.

lation and, therefore, remain spherical. We estimated the coagulation rate using the COmputer SIMulation of Aerosols (COSIMA) model of Naumann (2003), which was initialized with the size distribution measurements from the SPMS and with an estimated particle density of $1.25 \mathrm{~g} \mathrm{~cm}^{-3}$. The sticking probability was set to 1 in the model. Figure 6 shows the calculated coagulation rate together with the total concentration from SMPS for the experiment RUN2_10C (Fig. 4). A maximum concentration of $100000 \mathrm{~cm}^{-3}$ was reached, which led to a coagulation rate of $10 \mathrm{~cm}^{-3} \mathrm{~s}^{-1}$. At 17:30 UTC the time integral of the coagulation rate was $23000 \mathrm{~cm}^{-3}$, which gives an estimate of the number of particles involved in the coagulation process. This number is of the same order as the total number concentration $\left(25000 \mathrm{~cm}^{-3}\right)$ measured at the same time, indicating that the majority of the SOA particles were involved in coagulation processes and can be expected to have formed aggregates. As the particle number concentration decreases, the aggregation rate decreases to well below $1 \mathrm{~cm}^{-3} \mathrm{~s}^{-1}$, making coagulation 


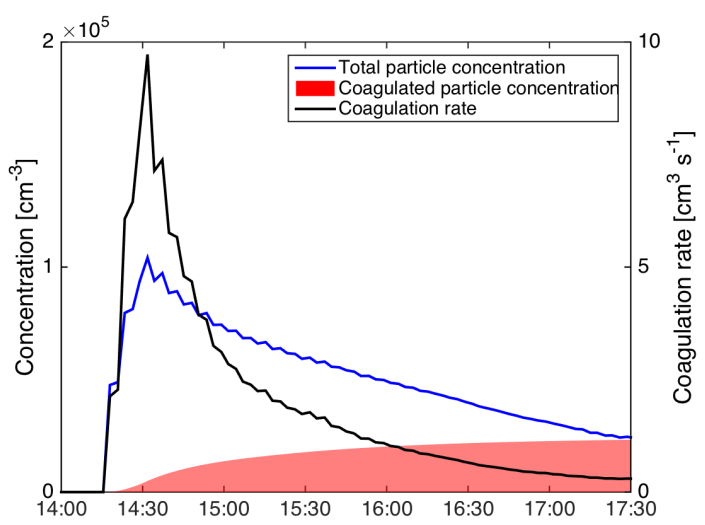

Figure 6. COSIMA model results for the coagulation rate of the SOA particles during experiment RUN2 at $-10^{\circ} \mathrm{C}$. The particle number concentration was integrated from the SMPS measurements between 20 and $500 \mathrm{~nm}$.

unimportant in the later phase. We can therefore expect that the SOA particles become aspherical aggregates at the beginning of the run and these aggregates subsequently grow by condenzation, forming quasi-spheroidal particles (Fig. 7), if the growth takes place when the particles are in a viscous phase.

The nucleation and growth conditions for the SOA particles in these experiments at the CLOUD chamber are unlikely to be fully representative of the conditions where SOA is formed in the atmosphere (e.g., Dal Maso et al., 2005; Kulmala et al., 2007, 2013; Kirkby et al., 2011; Riccobono et al., 2014). Viscous biogenic SOA particles have been observed to form in nucleation events in the boreal forest (Virtanen et al., 2010), where the concentrations of particles larger than $25 \mathrm{~nm}$ are typically below $100000 \mathrm{~cm}^{-3}$ (Dal Maso et al., 2005). Lower natural particle concentration may not promote the formation of aggregates, and therefore it is uncertain if natural SOA particles can be expected to be aspherical.

\subsection{Depolarization properties of the $\alpha$-pinene SOA particles}

We conducted a set of experiments with two different initial conditions. The primary experiments were started at low $\mathrm{RH}$, so that the nucleated SOA particles grew in an amorphous solid or semi-solid state. In contrast to these runs, one reference run was made at $-20^{\circ} \mathrm{C}$ with a high initial RH (60-70\%), so that the SOA particles started out in the aqueous phase state. The purpose of this reference run was to validate the depolarization method on a SOA system that would produce optically isotropic particles, and to exclude possible window artefacts. The SIMONE-Junior instrument is isolated from the chamber with two coated windows that do not change the depolarization ratio itself, but if material condenses to form a film on the windows, this might affect the measurements.

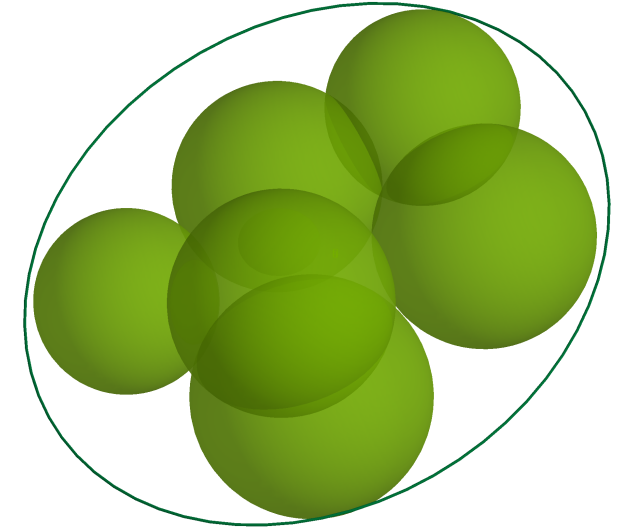

Figure 7. The SOA particles form aggregates at the early stage of their growth. After the coagulation rate has slowed, the aggregates grow by vapour condenzation to form non-spherical particles. The number of the single SOA particles in the aggregate is illustrative and does not necessary describe the real aggregates in the CLOUD chamber.

Figures 4 and 5 show the measured depolarization ratios of the $\alpha$-pinene SOA particles during the reference run and during RUN2_-10C. During all the low-RH experimental runs below $0{ }^{\circ} \mathrm{C}$, a depolarization ratio above LOD was measured, whereas during the reference run, the depolarization signal stayed below the depolarization threshold of 0.01 throughout the growth of the SOA particles. Based on this comparison, we can conclude that at low RH the measured depolarization ratio was due to the physical properties of the $\alpha$-pinene SOA particles and not a result of window artefacts.

The measured linear depolarization ratio averaged between 0.01 and 0.1 , and the circular depolarization ratio varied between 0.05 and 0.3 (Figs. 4 and 8). The circular depolarization ratio was always higher than linear depolarization ratio and both showed the same trend, i.e. both signals showed the oscillation maxima and minima at same locations. This is a common feature in depolarization measurements, and has been discussed in previous work by Mishchenko and Hovenier (1995). In theory, the circular depolarization ratio is more sensitive to small changes; this sensitivity should provide advantages over linear depolarization. However, in our case the LOD for the circular depolarization ratio was a factor of 2 higher than that for linear depolarization ratio. Thus, for this instrument, circular depolarization offered no clear advantage in our measurements.

A depolarization ratio that is above the LOD and above the background noise in these experiments suggests the presence of aspherical particles. In this case the magnitude of the depolarization signal depends on the size and shape of the particles. The increase in the depolarization at the beginning of the runs can be linked with the growth in the particle size, as can be expected from the $T$-matrix model (Fig. 2). A median particle diameter of $100 \mathrm{~nm}$ was sufficient to produce a noisefree depolarization ratio above the detection threshold; the 


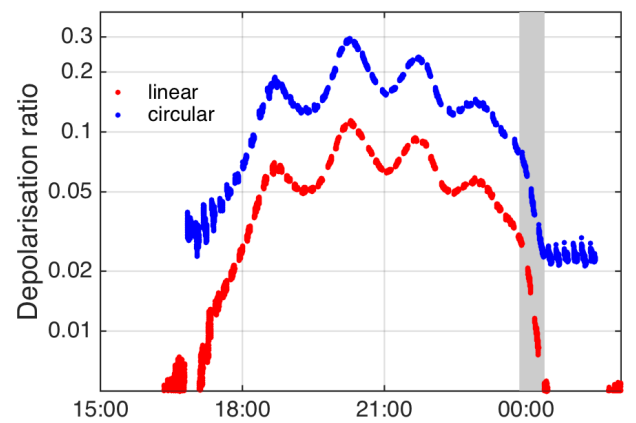

Figure 8. An example of alternating measurements of the linear and the circular depolarization ratios during RUN_-30C. Both depolarization ratios show oscillations with consistent minima and maxima. The shape transition is indicated by the grey area.

highest depolarization ratio was measured for $600 \mathrm{~nm}$ particles (Fig. 4). The maximum linear depolarization ratio varied between 0.05 and 0.1 , which corresponds to an aspect ratio of 0.8 to 0.74 according to the $T$-matrix model for spheroidal particles. The good agreement of the spheroidal model with our measurements support the hypothesized presence of SOA aggregates that grow quasi-spheroidal. Later in the experiments, condenzational growth drives the particles to become increasingly spherical, which is also indicated by our measurements, as a slight decrease in the depolarization ratio as the particle median diameter grew beyond $600 \mathrm{~nm}$.

In the early stages of experiment RUN2_-10C, we observed a single mode of growing $\alpha$-pinene SOA particles (Fig. 4) suggesting that the depolarization properties of the particles were produced by a single particle population. The narrowness of the size distribution could explain the oscillations that we frequently observed in the depolarization signal. It should be possible to confirm this conclusion by simulating the scattering properties of the evolving spheroidal particles, but that is beyond the scope of this work and will be addressed in a future study.

As described in Sect. 3.1, secondary nucleation occurred in some of our experiments, resulting in a bimodal size distribution. Figure 9 shows such a run with two growing modes. The main mode was somewhat wider than in the single-mode experiments, so we do not see clear oscillations in the depolarization signal. A new narrow mode was nucleated after 15:00 UTC, causing oscillations in the depolarization signal, as the new mode grew. The measured depolarization is, therefore, likely due to the net scattering and depolarization contributions from both of these modes, making the interpretation of the depolarization properties more challenging. Although the size distribution is not confined to a single size in the bimodal runs, the phase of the new particles was viscous, since the mode was formed before a significant increase in $\mathrm{RH}$. The asphericity of the new mode is also observed in the oscillations that are caused by the newly nucleated narrow mode.

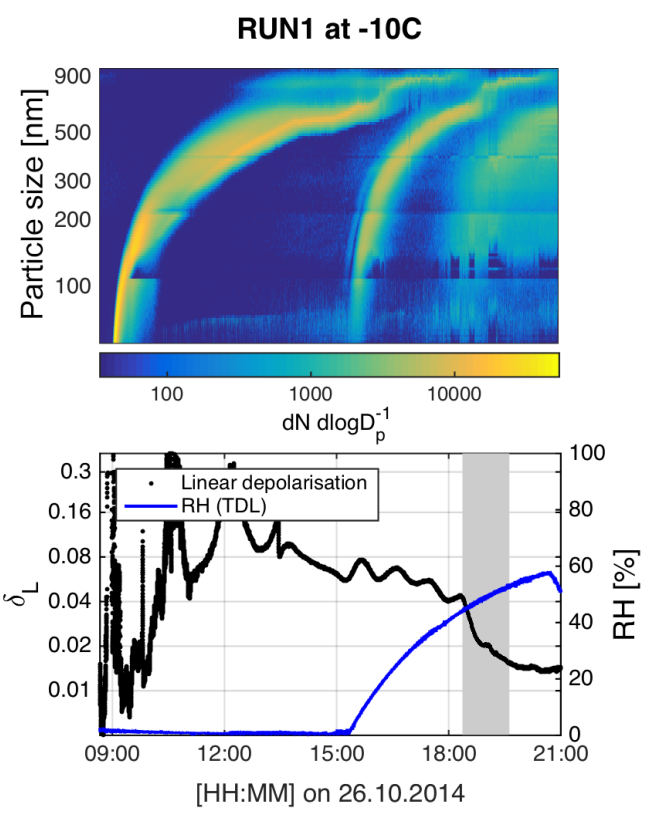

Figure 9. An example of a run with two growing SOA particle modes. The primary mode nucleated around 09:00 UTC and reached a median size of $600 \mathrm{~nm}$ around 15:00 UTC, when a second nucleation burst occurred. The new narrow mode produced the oscillations seen in the depolarization ratio after 15:00 UTC. The main mode was too wide and did not cause oscillations. These particles exhibited a phase transition starting around 18:25 UTC. The noise in the depolarization signal at the start of the experiment is caused by low signal in the backward detectors.

\subsection{The atomic oxygen to carbon ratio of the $\alpha$-pinene SOA}

The atomic $\mathrm{O} / \mathrm{C}$ ratio of SOA particles increases with particle ageing and is related to the hygroscopicity of the particles (Massoli et al., 2010; Duplissy et al., 2011; Lambe et al., 2011). The $\mathrm{O} / \mathrm{C}$ ratio affects the particle deliquescence point; in the case of $\alpha$-pinene SOA particles, we can expect the deliquescence point to be at higher temperatures with increasing $\mathrm{O} / \mathrm{C}$ ratio (Berkemeier et al., 2014). This might affect the particle shape and refractive index variation inside the particle, as higher hardness increases the possibility that the particles remain aspherical and thus induce a higher depolarization signal.

We measured the $\mathrm{O} / \mathrm{C}$ ratio using the $\mathrm{HR}-\mathrm{ToF}-\mathrm{AMS}$ (Aiken et al., 2007, 2008). The measured $\mathrm{O} / \mathrm{C}$ ratios varied from 0.23 to 0.29 with an average value of $0.25 \pm 0.04$ (average \pm standard deviation). Overall, the $\mathrm{O} / \mathrm{C}$ stays pretty constant throughout the experiment (Fig. 10). The average $\mathrm{O} / \mathrm{C}$ ratio (below 0.3) is similar to that reported by Pajunoja et al. (2014) of laboratory-produced $\alpha$-pinene SOA particles.

The SOA mass concentration shows a steep increase at the beginning of RUN2_-10C due to the continuous addition of ozone and $\alpha$-pinene to the chamber. At 15:35 UTC the 


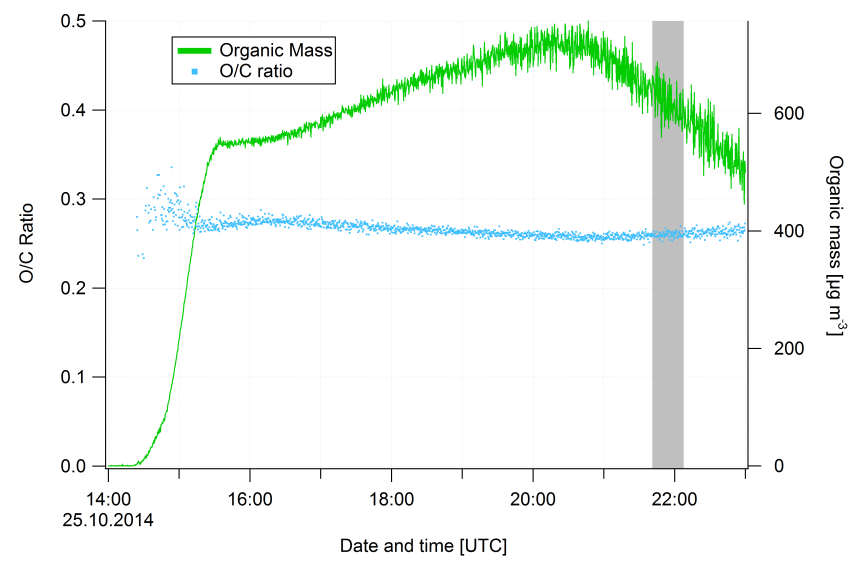

Figure 10. SOA mass concentration (green trace) and $\mathrm{O} / \mathrm{C}$ ratio of the SOA particles (blue points) measured with the HR-ToF-AMS for RUN1_-10C. The grey highlighted area represents the phase transition. The mass concentration represents SOA formed via $\alpha$ pinene ozonolysis; ozone was first added to the chamber during the period of steep growth at the beginning of the experiment. The decrease in SOA concentration towards the end of the experiment was due to dilution. The $\mathrm{O} / \mathrm{C}$ ratio stayed almost constant throughout the experiment.

SOA production rate decreased slightly as the fresh supply of ozone was reduced. After switching off the ozone supply at 20:20 UTC the formation of SOA was stopped and as a result the SOA concentration decreased due to dilution.

\subsection{Measured viscosity-/shape-transition RH as a function of temperature}

The depolarization signal in our experiments showed that the viscous $\alpha$-pinene SOA particles were non-spherical when the nucleation and growth of the particles occurred at low RH. As the RH increases, the viscous SOA particles start to take up water. The water uptake is slow, and proceeds gradually with increasing RH (Mikhailov et al., 2009; Zobrist et al., 2011). This is seen by the relatively slow shape transitions observed as the RH increases (Figs. 4, 8, and 9). In the aqueous phase, the surface area is minimized to reach an energetically favourable state. The minimization of the surface area results in shape change from aspherical to spherical. This change was observed in the depolarization ratio at the end of the low-RH runs, as the depolarization ratio decreased towards the instrument LOD. We determined the transition RH range from the measurements; the start of the transition was detected when the depolarization ratio started to decrease significantly. The end of the transition was detected when the depolarization ratio reached a constant level below the detection threshold (highlighted with grey in Figs. 4, 8, and 9). The $\mathrm{RH}$ value at the time the depolarization had decreased to a constant, zero level, describes the transition to an optically spherical shape. We label this RH value the viscosity-/shapetransition RH.

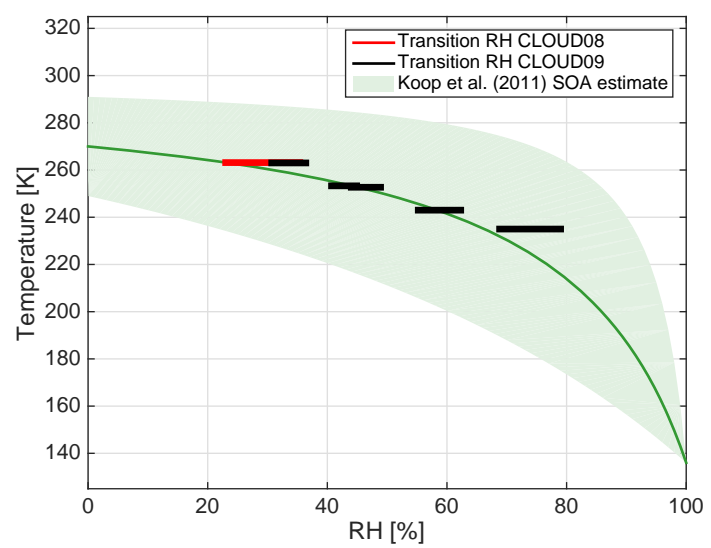

Figure 11. Transition RH at different temperatures. The horizontal lines show the $\mathrm{RH}$ range for the transition and the width of the lines represent the temperature uncertainty of $2 \mathrm{~K}$. The green curve is the generic SOA estimate from Koop et al. (2011) and the shaded area represents the upper and lower boundary for the estimate.

Figure 11 summarizes the complete RH range, where the viscosity/shape transition were observed for sub-zero temperatures. At $10^{\circ} \mathrm{C}$ a depolarization signal over LOD was not observed, suggesting that the particles were already in a liquid or low-viscous state at a RH of $12 \%$. Figure 11 shows that the measured viscosity-/shape-transition RH increases with decreasing temperature and has near-linear dependency on the temperature. At $-10{ }^{\circ} \mathrm{C}$ the viscosity/shape transition occurred at $\mathrm{RH}$ around $35 \%$ and at $-38^{\circ} \mathrm{C}$ the transition was observed at around $80 \% \mathrm{RH}$.

As explained above, our method does not directly measure the change in the viscosity but provides the critical $\mathrm{RH}$, where the water uptake is significantly enhanced and the particles start to relax rapidly due to the change in their viscosity. During this process the viscosity changes of the $\alpha$-pinene SOA particles are not limited by diffusion on water into the particles as the assumed water diffusion timescales can be expected to be of the order of seconds (Price et al., 2015; Lienhard et al., 2015). We can now use the observed relaxation time (of the order of $10 \mathrm{~min}$ ) to provide a rough estimate of the viscosity of the $\alpha$-pinene SOA particles during their viscosity/shape transition. However, it has to be kept in mind that the particle viscosity and the relaxation timescale are affected by the constant increase in the chamber RH by about $0.5 \% \mathrm{~min}^{-1}$, which increases the uncertainty of our estimate.

For the estimation of the particle viscosity, we used the method described in Pajunoja et al. (2014). We can assume a primary particle size of $400 \mathrm{~nm}$ in an SOA aggregate and a surface tension of $35 \mathrm{mN} \mathrm{m}^{-1}$ (Pajunoja et al., 2014). With these numbers we get an estimated viscosity of $10^{7} \mathrm{Pas}$. This value describes the viscosity during the viscosity/shape-transition period. Previous studies (e.g. RenbaumWolff et al., 2013; Bateman et al., 2014; Kidd et al., 2014; 
Pajunoja et al., 2014) have consider the viscosity of $\alpha$-pinene SOA particles at room temperatures. The studies have found that $\alpha$-pinene SOA particles are generally in liquid state already at $\mathrm{RH}>70 \%$ (Song et al., 2015). At colder temperatures we can expect the transition from viscous to liquid state is shifted to higher RH (Wang et al., 2014). As the measured viscosity/shape transitions generally took place at $\mathrm{RH}<70 \%$ the comparison with literature would suggest that albeit our SOA particles were spherical, they probably were not in liquid state after the transition. Therefore, our measured viscosity/shape transition would describe the change in the viscosity within a semi-solid material.

The viscosity of $\alpha$-pinene SOA and their glass-transition as a function of temperature and RH was estimated in the modelling study of Wang et al. (2014). Although the authors reported an increase in the glass-transition RH with decreasing temperature similar to what we observed in our experiments, the glass-transition RH that they report was always higher than our measured viscosity-/shape-transition RH; i.e. we found higher viscosities for the $\alpha$-pinene SOA particles. Furthermore, we compared our results with the Koop et al. (2011) generic SOA estimate that predicts the glasstransition temperature as a function of RH for a broad variety of SOA (Fig. 11). Overall the results agree well with the generic SOA estimate, and significantly reduce the uncertainty in that estimate in the specific case of $\alpha$-pinene SOA. Moreover, our results suggest the relationship between the transition $\mathrm{RH}$ and the temperature is more linear than predicted by Koop et al. (2011), although measurements at colder temperatures are missing.

Our method to detect the viscosity/shape transition of $\alpha$-pinene SOA is likely limited to laboratory experiments with high number concentrations promoting the formation of non-spherical SOA particle aggregates. Although our experimental data are not comprehensive enough to support the hypothesis that SOA particles in the troposphere might be non-spherical, we have demonstrated the first non-invasive method to study the viscosity of SOA particles formed by ozonolysis of gaseous $\alpha$-pinene. Moreover, the transition timescales that we observed, tens of minutes, are relevant to those that we can expect in the atmosphere. Therefore, the viscosity-/shape-transition RH that we report is relevant for the atmospheric processes. The present study focused on understanding the humidity effect on the viscosity-transition temperature of a single SOA component. The method could also be used in future studies to study SOA shape transitions of other SOA precursors.

\subsection{Atmospheric implications}

Atmospheric conditions where SOA is found cover the full range of RH (e.g. Hamed et al., 2011). The observed nearlinear dependence of the viscosity-/shape-transition temperature on RH is important for the low temperatures; our results imply that $\alpha$-pinene derived SOA particles may remain vis- cous in the upper troposphere up to an RH of almost $80 \%$. Moreover, the long time required for the transition from aspherical to spherical suggest that, even though the particles may temporarily be exposed to high $\mathrm{RH}$, they could remain in a viscous state. Hence, this kind of SOA particles may be able to act as IN, especially in the cirrus regime. The IN activity of the same $\alpha$-pinene SOA particles produced for the present study has been investigated in a parallel study (Ignatius et al., 2015) using a portable IN counter. They found that, at temperatures below or at the homogeneous freezing limit, the same particles acted as heterogeneous IN in the deposition and immersion modes. However, it is difficult to quantify the effect of the highly viscous SOA on climate; this should be addressed in future studies. Our results were restricted to temperatures above the homogeneous freezing threshold, but, to better understand the phase state of SOA in the cirrus regime, future studies at lower temperatures are needed.

\section{Conclusions}

The influence of temperature and relative humidity on the viscosity-transition of SOA particles is a subject of considerable uncertainty (Koop et al., 2011). Here, we estimated the viscosity of $\alpha$-pinene SOA at different atmospherically relevant temperatures and relative humidities using a new optical and non-invasive in situ method. We used near-backscattering depolarization to measure the asphericity of the SOA particles and their shape change to spherical that took place at viscosity of around $10^{7} \mathrm{Pas}$. The relaxation timescales were observed to be $10 \mathrm{~s}$ of minutes timescales relevant for atmospheric processes. Thus, we conclude that the viscosity-/shape-transition RH defined by our method provides a quantity that is directly relevant for glassy transitions of SOA particles in the atmosphere, although the viscosity of the SOA particles cannot be directly determined from our measurements.

We showed that $\alpha$-pinene SOA particles acquire a nonspherical shape due to coagulation in our chamber experiments. The non-spherical shape persists when the particles are nucleated and grown under low RH. This non-spherical shape is a result of the viscosity of the particles and this viscous state can be detected with depolarization measurements for SOA particles larger than $100 \mathrm{~nm}$.

We observed viscosity/shape transition in six experiments conducted at four temperatures. We found that this viscosity/shape-transition temperature depends linearly on $\mathrm{RH}$; this increases the likelihood that $\alpha$-pinene SOA particles persist in a viscous state at low temperatures, making them potential ice nuclei (IN) in the cirrus cloud regime. Generally, our results improve the understanding of the viscosity of $\alpha$-pinene SOA at temperatures above the homogeneous freezing point. The influence of highly viscous SOA on climate should be further assessed in future modelling studies. 
Acknowledgements. We would like to thank the two anonymous referees for their valuable comments. We thank CERN for supporting CLOUD with important technical and financial resources. We thank the CLOUD-TRAIN community and specially all the ITN students for their help and support. This research has received funding from the Seventh Framework Programme of the European Union (Marie Curie-Networks for Initial Training MC-ITN CLOUD-TRAIN no. 316662), from Swiss National Science Foundation (SNSF) grant number 200021_140663, from US National Science Foundation grants AGS-1447056 and AGS-1439551, from Dreyfus Award EP-11-117, from German Federal Ministry of Education and Research BMBF (project no. 01LK1222A and B), from the Davidow Foundation, and from the funding of the German Federal Ministry of Education and Research (BMBF) through the CLOUD12 project.

The article processing charges for this open-access publication were covered by a Research

Centre of the Helmholtz Association.

Edited by: T. Koop

\section{References}

Adler, G., Koop, T., Haspel, C., Taraniuk, I., Moise, T., Koren, I., Heiblum, R. H., and Rudich, Y.: Formation of highly porous aerosol particles by atmospheric freeze-drying in ice clouds, P. Natl. Acad. Sci. USA, 110, 20414-20419, doi:10.1073/pnas.1317209110, 2013.

Aiken, A. C., DeCarlo, P. F., and Jimenez, J. L.: Elemental analysis of organic species with electron ionization high-resolution mass spectrometry, Anal. Chem., 79, 8350-8358, 2007.

Aiken, A. C., Decarlo, P. F., Kroll, J. H., Worsnop, D. R., Huffman, J. A., Docherty, K. S., Ulbrich, I. M., Mohr, C., Kimmel, J. R., Sueper, D., Sun, Y., Zhang, Q., Trimborn, A., Northway, M., Ziemann, P. J., Canagaratna, M. R., Onasch, T. B., Alfarra, M. R., Prevot, A. S. H., Dommen, J., Duplissy, J., Metzger, A., Baltensperger, U., and Jimenez, J. L.: O / C and OM / OC ratios of primary, secondary, and ambient organic aerosols with high-resolution time-of-flight aerosol mass spectrometry, Environ. Sci. Technol., 42, 4478-4485, 2008.

Bateman, A. P., Belassein, H., and Martin, S. T.: Impactor apparatus for the study of particle rebound: Relative humidity and capillary forces, Aerosol Sci. Tech., 48, 42-52, 2014.

Berkemeier, T., Shiraiwa, M., Pöschl, U., and Koop, T.: Competition between water uptake and ice nucleation by glassy organic aerosol particles, Atmos. Chem. Phys., 14, 12513-12531, doi:10.5194/acp-14-12513-2014, 2014.

Dal Maso, M., Kulmala, M., Riipinen, I., Wagner, R., Hussein, T., Aalto, P. P., and Lehtinen, K. E.: Formation and growth of fresh atmospheric aerosols: eight years of aerosol size distribution data from SMEAR II, Hyytiala, Finland, Boreal Environ. Res., 10, 323-336, 2005.

Dlugach, J. M. and Mishchenko, M. I.: Scattering properties of heterogeneous mineral particles with absorbing inclusions, J. Quant. Spectrosc. Ra., 162, 89-94, 2015.

Duplissy, J., DeCarlo, P. F., Dommen, J., Alfarra, M. R., Metzger, A., Barmpadimos, I., Prevot, A. S. H., Weingartner, E.,
Tritscher, T., Gysel, M., Aiken, A. C., Jimenez, J. L., Canagaratna, M. R., Worsnop, D. R., Collins, D. R., Tomlinson, J., and Baltensperger, U.: Relating hygroscopicity and composition of organic aerosol particulate matter, Atmos. Chem. Phys., 11, 1155-1165, doi:10.5194/acp-11-1155-2011, 2011.

Duplissy, J., Merikanto, J., Franchin, A., Tsagkogeorgas, G., Kangasluoma, J., Wimmer, D., Vuollekoski, H., Schobesberger, S., Lehtipalo, K., Flagan, R., Brus, D., Donahue, N. M., Vehkämäki, H., Almeida, J., Amorim, A., Barmet, P., Bianchi, F., Breitenlechner, M., Dunne, E. M., Guida, R., Henschel, H., Junninen, H., Kirkby, J., Kürten, A., Kupc, A., Määttänen, A., Makhmutov, V., Mathot, S., Nieminen, T., Onnela, A., Praplan, A. P., Riccobono, F., Rondo, L., Steiner, G., Tome, A., Walther, H., Baltensperger, U., Carslaw, K. S., Dommen, J., Hansel, A., Petäjä, T., Sipilä, M., Stratmann, F., Vrtala, A., Wagner, P. E., Worsnop, D. R., Curtius, J., and Kulmala, M.: Effect of ions on sulfuric acid-water binary particle formation II: Experimental data and comparison with QC-normalized classical nucleation theory, J. Geophys. Res.Atmos., 120, 1752-1775, doi:10.1002/2015JD023539, 2015.

Fahey, D. W., Gao, R.-S., Möhler, O., Saathoff, H., Schiller, C., Ebert, V., Krämer, M., Peter, T., Amarouche, N., Avallone, L. M., Bauer, R., Bozóki, Z., Christensen, L. E., Davis, S. M., Durry, G., Dyroff, C., Herman, R. L., Hunsmann, S., Khaykin, S. M., Mackrodt, P., Meyer, J., Smith, J. B., Spelten, N., Troy, R. F., Vömel, H., Wagner, S., and Wienhold, F. G.: The AquaVIT-1 intercomparison of atmospheric water vapor measurement techniques, Atmos. Meas. Tech., 7, 3177-3213, doi:10.5194/amt-7-3177-2014, 2014.

Guenther, A., Hewitt, C. N., Erickson, D., Fall, R., Geron, C., Graedel, T., Harley, P., Klinger, L., Lerdau, M., McKay, W., Pierce, T., Scholes, B., Steinbrecher, R., Tallamraju, R., Taylor, J., and Zimmerman, P.: A global model of natural volatile organic compound emissions, J. Geophys. Res.-Atmos., 100, 8873-8892, 1995.

Hallquist, M., Wenger, J. C., Baltensperger, U., Rudich, Y., Simpson, D., Claeys, M., Dommen, J., Donahue, N. M., George, C., Goldstein, A. H., Hamilton, J. F., Herrmann, H., Hoffmann, T., Iinuma, Y., Jang, M., Jenkin, M. E., Jimenez, J. L., Kiendler-Scharr, A., Maenhaut, W., McFiggans, G., Mentel, Th. F., Monod, A., Prévôt, A. S. H., Seinfeld, J. H., Surratt, J. D., Szmigielski, R., and Wildt, J.: The formation, properties and impact of secondary organic aerosol: current and emerging issues, Atmos. Chem. Phys., 9, 5155-5236, doi:10.5194/acp-9-51552009, 2009.

Hamed, A., Korhonen, H., Sihto, S.-L., Joutsensaari, J., Järvinen, H., Petäjä, T., Arnold, F., Nieminen, T., Kulmala, M., Smith, J. N., Lehtinen, K. E. J., and Laaksonen, A.: The role of relative humidity in continental new particle formation, J. Geophys. Res.-Atmos., 116, D03202, doi:10.1029/2010JD014186, 2011.

Hirsikko, A., O'Connor, E. J., Komppula, M., Korhonen, K., Pfüller, A., Giannakaki, E., Wood, C. R., Bauer-Pfundstein, M., Poikonen, A., Karppinen, T., Lonka, H., Kurri, M., Heinonen, J., Moisseev, D., Asmi, E., Aaltonen, V., Nordbo, A., Rodriguez, E., Lihavainen, H., Laaksonen, A., Lehtinen, K. E. J., Laurila, T., Petäjä, T., Kulmala, M., and Viisanen, Y.: Observing wind, aerosol particles, cloud and precipitation: Finland's new groundbased remote-sensing network, Atmos. Meas. Tech., 7, 13511375, doi:10.5194/amt-7-1351-2014, 2014. 
Hoyle, C. R., Boy, M., Donahue, N. M., Fry, J. L., Glasius, M., Guenther, A., Hallar, A. G., Huff Hartz, K., Petters, M. D., Petäjä, T., Rosenoern, T., and Sullivan, A. P.: A review of the anthropogenic influence on biogenic secondary organic aerosol, Atmos. Chem. Phys., 11, 321-343, doi:10.5194/acp-11-321-2011, 2011.

Hoyle, C. R., Fuchs, C., Järvinen, E., Saathoff, H., Dias, A., El Haddad, I., Gysel, M., Coburn, S. C., Tröstl, J., Bernhammer, A.-K., Bianchi, F., Breitenlechner, M., Corbin, J. C., Craven, J., Donahue, N. M., Duplissy, J., Ehrhart, S., Frege, C., Gordon, H., Höppel, N., Heinritzi, M., Kristensen, T. B., Molteni, U., Nichman, L., Pinterich, T., Prévôt, A. S. H., Simon, M., Slowik, J. G., Steiner, G., Tomé, A., Vogel, A. L., Volkamer, R., Wagner, A. C., Wagner, R., Wexler, A. S., Williamson, C., Winkler, P. M., Yan, C., Amorim, A., Dommen, J., Curtius, J., Gallagher, M. W., Flagan, R. C., Hansel, A., Kirkby, J., Kulmala, M., Möhler, O., Stratmann, F., Worsnop, D. R., and Baltensperger, U.: Aqueous phase oxidation of sulphur dioxide by ozone in cloud droplets, Atmos. Chem. Phys., 16, 1693-1712, doi:10.5194/acp-16-16932016, 2016.

Huang, R.-J., Zhang, Y., Bozzetti, C., Ho, K.-F., Cao, J.-J., Han, Y., Daellenbach, K. R., Slowik, J. G., Platt, S. M., Canonaco, F., Zotter, P., Wolf, R., Pieber, S. M., Bruns, E. A., Crippa, M., Ciarelli, G., Piazzalunga, A., Schwikowski, M., Abbaszade, G., SchnelleKreis, J., Zimmermann, R., An, Z., Szidat, S., Baltensperger, U., El Haddad, I., and Prévôt, A. S. H.: High secondary aerosol contribution to particulate pollution during haze events in China, Nature, 514, 218-222, 2014.

Ignatius, K., Kristensen, T. B., Järvinen, E., Nichman, L., Fuchs, C., Gordon, H., Herenz, P., Hoyle, C. R., Duplissy, J., Garimella, S., Dias, A., Frege, C., Höppel, N., Tröstl, J., Wagner, R., Yan, C., Amorim, A., Baltensperger, U., Curtius, J., Donahue, N. M., Gallagher, M. W., Kirkby, J., Kulmala, M., Möhler, O., Saathoff, H., Schnaiter, M., Tomé, A., Virtanen, A., Worsnop, D., and Stratmann, F.: Heterogeneous ice nucleation of viscous secondary organic aerosol produced from ozonolysis of a-pinene, Atmos. Chem. Phys. Discuss., 15, 35719-35752, doi:10.5194/acpd-1535719-2015, 2015.

Jimenez, J. L., Canagaratna, M. R., Donahue, N. M., Prevot, A. S. H., Zhang, Q., Kroll, J. H., DeCarlo, P. F., Allan, J. D., Coe, H., Ng, N. L., Aiken, A. C., Docherty, K. S., Ulbrich, I. M., Grieshop, A. P., Robinson, A. L., Duplissy, J., Smith, J. D., Wilson, K. R., Lanz, V. A., Hueglin, C., Sun, Y. L., Tian, J., Laaksonen, A., Raatikainen, T., Rautiainen, J., Vaattovaara, P., Ehn, M., Kulmala, M., Tomlinson, J. M., Collins, D. R., Cubison, M. J., E., Dunlea, J., Huffman, J. A., Onasch, T. B., Alfarra, M. R., Williams, P. I., Bower, K., Kondo, Y., Schneider, J., Drewnick, F., Borrmann, S., Weimer, S., Demerjian, K., Salcedo, D., Cottrell, L., Griffin, R., Takami, A., Miyoshi, T., Hatakeyama, S., Shimono, A., Sun, J. Y., Zhang, Y. M., Dzepina, K., Kimmel, J. R., Sueper, D., Jayne, J. T., Herndon, S. C., Trimborn, A. M., Williams, L. R., Wood, E. C., Middlebrook, A. M., Kolb, C. E., Baltensperger, U., and Worsnop, D. R.: Evolution of organic aerosols in the atmosphere, Science, 326, 1525-1529, 2009.

Kim, H., Barkley, B., and Paulson, S. E.: Real refractive indices of $\alpha$-and $\beta$-pinene and toluene secondary organic aerosols generated from ozonolysis and photo-oxidation, J. Geophys. Res.Atmos., 115, D24212, doi:10.1029/2010JD014549, 2010.
Kidd, C., Perraud, V., Wingen, L. M., and Finlayson-Pitts, B. J.: Integrating phase and composition of secondary organic aerosol from the ozonolysis of $\alpha$-pinene, P. Natl. Acad. Sci., 111, 75527557, 2014.

Kirkby, J., Curtius, J., Almeida, J., Dunne, E., Duplissy, J., Ehrhart, S., Franchin, A., Gagné, S., Ickes, L., Kürten, A., Kupc, A., Metzger, A., Riccobono, F., Rondo, L., Schobesberger, S., Tsagkogeorgas, G., Wimmer, D., Amorim, A., Bianchi, F., Breitenlechner, M., David, A., Dommen, J., Downard, A., Ehn, M., Flagan, R. C., Haider, S., Hansel, A., Hauser, D., Jud, W., Junninen, H., Kreissl, F., Kvashin, A., Laaksonen, A., Lehtipalo, K., Lima, J., Lovejoy, E. R., Makhmutov, V., Mathot, S., Mikkilä, J., Minginette, P., Mogo, S., Nieminen, T., Onnela, A., Pereira, P., Petäjä, T., Schnitzhofer, R., Seinfeld, J. H., Sipilä, M., Stozhkov, Y., Stratmann, F., Tomé, A., Vanhanen, J., Viisanen, Y., Vrtala, A., Wagner, P. E., Walther, H., Weingartner, E., Wex, H., Winkler, P. M., Carslaw, K. S., Worsnop, D. R., Baltensperger, U., and Kulmala, M.: Role of sulphuric acid, ammonia and galactic cosmic rays in atmospheric aerosol nucleation, Nature, 476, 429-433, 2011.

Koop, T., Bookhold, J., Shiraiwa, M., and Pöschl, U.: Glass transition and phase state of organic compounds: dependency on molecular properties and implications for secondary organic aerosols in the atmosphere, Phys. Chem. Chem. Phys., 13, 19238-19255, 2011.

Kulmala, M., Riipinen, I., Sipilä, M., Manninen, H. E., Petäjä, T., Junninen, H., Dal Maso, M., Mordas, G., Mirme, A., Vana, M., Hirsikko, A., Laakso, L., Harrison, R. M., Hanson, I., Leung, C., Lehtinen, K. E. J., and Kerminen, V. M.: Toward direct measurement of atmospheric nucleation, Science, 318, 89-92, 2007.

Kulmala, M., Kontkanen, J., Junninen, H., Lehtipalo, K., Manninen, H. E., Nieminen, T., Petäjä, T., Sipilä, M., Schobesberger, S., Rantala, P., Franchin, A., Jokinen, T., Järvinen, E., Äijälä, M., Kangasluoma, J., Hakala, J., Aalto, P. P., Paasonen, P., Mikkilä, J., Vanhanen, J., Aalto, J., Hakola, H., Makkonen, U., Ruuskanen, T., Mauldin III, R. L., Duplissy, J., Vehkamäki, H., Bäck, J., Kortelainen, A., Riipinen, I., Kurtén, T., Johnston, M. V., Smith, J. N., Ehn, M., Mentel, T. F., Lehtinen, K. E. J., Laaksonen, A., Kerminen, V. M., and Worsnop, D. R.: Direct observations of atmospheric aerosol nucleation, Science, 339, 943-946, 2013.

Laaksonen, A., Kulmala, M., O’Dowd, C. D., Joutsensaari, J., Vaattovaara, P., Mikkonen, S., Lehtinen, K. E. J., Sogacheva, L., Dal Maso, M., Aalto, P., Petäjä, T., Sogachev, A., Yoon, Y. J., Lihavainen, H., Nilsson, D., Facchini, M. C., Cavalli, F., Fuzzi, S., Hoffmann, T., Arnold, F., Hanke, M., Sellegri, K., Umann, B., Junkermann, W., Coe, H., Allan, J. D., Alfarra, M. R., Worsnop, D. R., Riekkola, M.-L., Hyötyläinen, T., and Viisanen, Y.: The role of VOC oxidation products in continental new particle formation, Atmos. Chem. Phys., 8, 2657-2665, doi:10.5194/acp-82657-2008, 2008.

Lambe, A. T., Onasch, T. B., Massoli, P., Croasdale, D. R., Wright, J. P., Ahern, A. T., Williams, L. R., Worsnop, D. R., Brune, W. H., and Davidovits, P.: Laboratory studies of the chemical composition and cloud condensation nuclei $(\mathrm{CCN})$ activity of secondary organic aerosol (SOA) and oxidized primary organic aerosol (OPOA), Atmos. Chem. Phys., 11, 8913-8928, doi:10.5194/acp11-8913-2011, 2011. 
Li, X., Taflove, A., and Backman, V.: Quantitative analysis of depolarization of backscattered light by stochastically inhomogeneous dielectric particles, Opt. Lett., 30, 902-904, 2005.

Lienhard, D. M., Huisman, A. J., Krieger, U. K., Rudich, Y., Marcolli, C., Luo, B. P., Bones, D. L., Reid, J. P., Lambe, A. T., Canagaratna, M. R., Davidovits, P., Onasch, T. B., Worsnop, D. R., Steimer, S. S., Koop, T., and Peter, T.: Viscous organic aerosol particles in the upper troposphere: diffusivity-controlled water uptake and ice nucleation?, Atmos. Chem. Phys., 15, 1359913613, doi:10.5194/acp-15-13599-2015, 2015.

Massoli, P., Lambe, A., Ahern, A., Williams, L., Ehn, M., Mikkilä, J., Canagaratna, M., Brune, W., Onasch, T., Jayne, J., Petäjä, T., Kulmala, M., Laaksonen, A., Kolb, C. E., Davidovits, P., and Worsnop, D. R.: Relationship between aerosol oxidation level and hygroscopic properties of laboratory generated secondary organic aerosol (SOA) particles, Geophys. Res. Lett., 37, L24801, doi:10.1029/2010GL045258, 2010.

Mikhailov, E., Vlasenko, S., Martin, S. T., Koop, T., and Pöschl, U.: Amorphous and crystalline aerosol particles interacting with water vapor: conceptual framework and experimental evidence for restructuring, phase transitions and kinetic limitations, Atmos. Chem. Phys., 9, 9491-9522, doi:10.5194/acp-9-9491-2009, 2009.

Mishchenko, M. and Hovenier, J.: Depolarization of light backscattered by randomly oriented nonspherical particles, Opt. Lett., 20, 1356-1358, 1995.

Mishchenko, M., Travis, L., and Mackowski, D.: T-matrix computations of light scattering by nonspherical particles: a review, J. Quant. Spectrosc. Ra., 55, 535-575, 1996.

Murray, B. J., Wilson, T. W., Dobbie, S., Cui, Z., Al-Jumur, S. M., Möhler, O., Schnaiter, M., Wagner, R., Benz, S., Niemand, M., Saathoff, H., Ebert, V., Wagner, S., and Kärcher, B.: Heterogeneous nucleation of ice particles on glassy aerosols under cirrus conditions, Nat. Geosci., 3, 233-237, 2010.

Naumann, K.-H.: COSIMA - a computer program simulating the dynamics of fractal aerosols, J. Aerosol Sci., 34, 1371-1397, 2003.

Nel, A.: Air pollution-related illness: effects of particles, Science, 308, 804-806, doi:10.1126/science.1108752, 2005.

Pajunoja, A., Malila, J., Hao, L., Joutsensaari, J., Lehtinen, K. E., and Virtanen, A.: Estimating the viscosity range of SOA particles based on their coalescence time, Aerosol Sci. Tech., 48, i-iv, 2014.

Pajunoja, A., Lambe, A. T., Hakala, J., Rastak, N., Cummings, M. J., Brogan, J. F., Hao, L., Paramonov, M., Hong, J., Prisle, N. L., Malila, J., Romakkaniemi, S., Lehtinen, K. E. J., Laaksonen, A., Kulmala, M., Massoli, P., Onasch, T. B., Donahue, N. M., Riipinen, I., Davidovits, P., Worsnop, D. R., Petäjä, T., and Virtanen, A.: Adsorptive uptake of water by semisolid secondary organic aerosols, Geophys. Res. Lett., 42, 3063-3068, 2015.

Price, H. C., Mattsson, J., Zhang, Y., Bertram, A. K., Davies, J. F., Grayson, J. W., Martin, S. T., O’Sullivan, D., Reid, J. P., Rickards, A. M. J., and Murray, B. J.: Water diffusion in atmospherically relevant $\alpha$-pinene secondary organic material, Chem. Sci., 6, 4876-4883, 2015.

Redmond, H. and Thompson, J. E.: Evaluation of a quantitative structure-property relationship (QSPR) for predicting mid- visible refractive index of secondary organic aerosol (SOA), Phys. Chem. Chem. Phys., 13, 6872-6882, 2011.

Renbaum-Wolff, L., Grayson, J. W., Bateman, A. P., Kuwata, M., Sellier, M., Murray, B. J., Shilling, J. E., Martin, S. T., and Bertram, A. K.: Viscosity of $\alpha$-pinene secondary organic material and implications for particle growth and reactivity, P. Natl. Acad. Sci. USA, 110, 8014-8019, doi:10.1073/pnas.1219548110, 2013.

Riccobono, F., Schobesberger, S., Scott, C. E., Dommen, J., Ortega, I. K., Rondo, L., Almeida, J., Amorim, A., Bianchi, F., Breitenlechner, M., David, A., Downard, A., Dunne, E. M., Duplissy, J., Ehrhart, S., Flagan, R. C., Franchin, A., Hansel, A., Junninen, H., Kajos, M., Keskinen, M., Kupc, A., Kürten, A., Kvashin, A. N., Laaksonen, A., Lehtipalo, K., Makhmutov, V., Mathot, S., Nieminen, T., Onnela, A., Petäjä, T., Praplan, A. P., Santos, F. D., Schallhart, S., Seinfeld, J. H., Sipilä, M., Spracklen, D. V., Stozhkov, Y., Stratmann, F., Tomé, A., Tsagkogeorgas, G., Vaattovaara, P., Viisanen, Y., Vrtala, A., Wagner, P. E., Weingartner, E., Wex, H., Wimmer, D., Carslaw, K. S., Curtius, J., Donahue, N. M., Kirkby, J., Kulmala, M., Worsnop, D. R., and Baltensperger, U.: Oxidation products of biogenic emissions contribute to nucleation of atmospheric particles, Science, 344, 717721, 2014.

Riipinen, I., Yli-Juuti, T., Pierce, J. R., Petäjä, T., Worsnop, D. R., Kulmala, M., and Donahue, N. M.: The contribution of organics to atmospheric nanoparticle growth, Nat. Geosci., 5, 453-458, 2012.

Sakai, T., Nagai, T., Zaizen, Y., and Mano, Y.: Backscattering linear depolarization ratio measurements of mineral, sea-salt, and ammonium sulfate particles simulated in a laboratory chamber, Appl. Optics, 49, 4441-4449, 2010.

Sassen, K.: The polarization lidar technique for cloud research: A review and current assessment, B. Am. Meteorol. Soc., 72, 1848-1866, 1991.

Saukko, E., Lambe, A. T., Massoli, P., Koop, T., Wright, J. P., Croasdale, D. R., Pedernera, D. A., Onasch, T. B., Laaksonen, A., Davidovits, P., Worsnop, D. R., and Virtanen, A.: Humiditydependent phase state of SOA particles from biogenic and anthropogenic precursors, Atmos. Chem. Phys., 12, 7517-7529, doi:10.5194/acp-12-7517-2012, 2012.

Schill, G. P., De Haan, D. O., and Tolbert, M. A.: Heterogeneous ice nucleation on simulated secondary organic aerosol, Environ. Sci. Technol., 48, 1675-1682, 2014.

Schnaiter, M., Linke, C., Möhler, O., Naumann, K.-H., Saathoff, H., Wagner, R., Schurath, U., and Wehner, B.: Absorption amplification of black carbon internally mixed with secondary organic aerosol, J. Geophys. Res.-Atmos., 110, D19204, doi:10.1029/2005JD006046, 2005.

Schnaiter, M., Büttner, S., Möhler, O., Skrotzki, J., Vragel, M., and Wagner, R.: Influence of particle size and shape on the backscattering linear depolarisation ratio of small ice crystals - cloud chamber measurements in the context of contrail and cirrus microphysics, Atmos. Chem. Phys., 12, 10465-10484, doi:10.5194/acp-12-10465-2012, 2012.

Schnitzhofer, R., Metzger, A., Breitenlechner, M., Jud, W., Heinritzi, M., De Menezes, L.-P., Duplissy, J., Guida, R., Haider, S., Kirkby, J., Mathot, S., Minginette, P., Onnela, A., Walther, H., Wasem, A., Hansel, A., and the CLOUD Team: Characterisation of organic contaminants in the CLOUD chamber at CERN, At- 
mos. Meas. Tech., 7, 2159-2168, doi:10.5194/amt-7-2159-2014, 2014.

Shiraiwa, M., Ammann, M., Koop, T., and Pöschl, U.: Gas uptake and chemical aging of semisolid organic aerosol particles, P. Natl. Acad. Sci. USA, 108, 11003-11008, 2011.

Song, M., Liu, P. F., Hanna, S. J., Li, Y. J., Martin, S. T., and Bertram, A. K.: Relative humidity-dependent viscosities of isoprene-derived secondary organic material and atmospheric implications for isoprene-dominant forests, Atmos. Chem. Phys., 15, 5145-5159, doi:10.5194/acp-15-5145-2015, 2015.

Swietlicki, E., HANSSON, H.-C., Hämeri, K., Svenningsson, B., Massling, A., McFiggans, G., McMurry, P., Petäjä, T., Tunved, P., Gysel, M., Topping, D. Weingartner, E., Baltensperger, U., Rissler, J., Wiedensohler, A., and Kulmala, M.: Hygroscopic properties of submicrometer atmospheric aerosol particles measured with H-TDMA instruments in various environments - a review, Tellus B, 60, 432-469, 2008.

Tunved, P., Hansson, H.-C., Kerminen, V.-M., Ström, J., Dal Maso, M., Lihavainen, H., Viisanen, Y., Aalto, P., Komppula, M., and Kulmala, M.: High natural aerosol loading over boreal forests, Science, 312, 261-263, 2006.

Virtanen, A., Joutsensaari, J., Koop, T., Kannosto, J., Yli-Pirilä, P., Leskinen, J., Mäkelä, J. M., Holopainen, J. K., Pöschl, U., Kulmala, M., Worsnop, D. R., and Laaksonen, A.: An amorphous solid state of biogenic secondary organic aerosol particles, Nature, 467, 824-827, 2010.

Virtanen, A., Kannosto, J., Kuuluvainen, H., Arffman, A., Joutsensaari, J., Saukko, E., Hao, L., Yli-Pirilä, P., Tiitta, P., Holopainen, J. K., Keskinen, J., Worsnop, D. R., Smith, J. N., and Laaksonen, A.: Bounce behavior of freshly nucleated biogenic secondary organic aerosol particles, Atmos. Chem. Phys., 11, 8759-8766, doi:10.5194/acp-11-8759-2011, 2011.

Voigtländer, J., Duplissy, J., Rondo, L., Kürten, A., and Stratmann, F.: Numerical simulations of mixing conditions and aerosol dynamics in the CERN CLOUD chamber, Atmos. Chem. Phys., 12, 2205-2214, doi:10.5194/acp-12-2205-2012, 2012.
Wagner, R., Möhler, O., Saathoff, H., Schnaiter, M., Skrotzki, J., Leisner, T., Wilson, T. W., Malkin, T. L., and Murray, B. J.: Ice cloud processing of ultra-viscous/glassy aerosol particles leads to enhanced ice nucleation ability, Atmos. Chem. Phys., 12, 85898610, doi:10.5194/acp-12-8589-2012, 2012.

Wang, B., Lambe, A. T., Massoli, P., Onasch, T. B., Davidovits, P., Worsnop, D. R., and Knopf, D. A.: The deposition ice nucleation and immersion freezing potential of amorphous secondary organic aerosol: pathways for ice and mixedphase cloud formation, J. Geophys. Res.-Atmos., 117, D16209, doi:10.1029/2012JD018063, 2012.

Wang, B., O’Brien, R. E., Kelly, S. T., Shilling, J. E., Moffet, R. C., Gilles, M. K., and Laskin, A.: Reactivity of liquid and semisolid secondary organic carbon with chloride and nitrate in atmospheric aerosols, J. Phys. Chem. A., 119, 4498-4508, 2014.

Wilson, T. W., Murray, B. J., Wagner, R., Möhler, O., Saathoff, H., Schnaiter, M., Skrotzki, J., Price, H. C., Malkin, T. L., Dobbie, S., and Al-Jumur, S. M. R. K.: Glassy aerosols with a range of compositions nucleate ice heterogeneously at cirrus temperatures, Atmos. Chem. Phys., 12, 8611-8632, doi:10.5194/acp-128611-2012, 2012.

Zhang, Y., Sanchez, M. S., Douet, C., Wang, Y., Bateman, A. P., Gong, Z., Kuwata, M., Renbaum-Wolff, L., Sato, B. B., Liu, P. F., Bertram, A. K., Geiger, F. M., and Martin, S. T.: Changing shapes and implied viscosities of suspended submicron particles, Atmos. Chem. Phys., 15, 7819-7829, doi:10.5194/acp-15-78192015, 2015.

Zobrist, B., Marcolli, C., Pedernera, D. A., and Koop, T.: Do atmospheric aerosols form glasses?, Atmos. Chem. Phys., 8, 52215244, doi:10.5194/acp-8-5221-2008, 2008.

Zobrist, B., Soonsin, V., Luo, B. P., Krieger, U. K., Marcolli, C., Peter, T., and Koop, T.: Ultra-slow water diffusion in aqueous sucrose glasses, Phys. Chem. Chem. Phys., 13, 3514-3526, 2011. 